Atmos. Chem. Phys., 13, 11059-11071, 2013

www.atmos-chem-phys.net/13/11059/2013/

doi:10.5194/acp-13-11059-2013

(c) Author(s) 2013. CC Attribution 3.0 License.

\title{
Stable carbon isotope ratios of toluene in the boundary layer and the lower free troposphere
}

\author{
J. Wintel ${ }^{1}$, E. Hösen ${ }^{1}$, R. Koppmann ${ }^{1}$, M. Krebsbach ${ }^{1}$, A. Hofzumahaus ${ }^{2}$, and F. Rohrer ${ }^{2}$ \\ ${ }^{1}$ Physics Department, University of Wuppertal, Wuppertal, Germany \\ ${ }^{2}$ Institute for Energy and Climate Research (IEK-8, Troposphere), Research Centre Jülich, Jülich, Germany \\ Correspondence to: J. Wintel (wintel@uni-wuppertal.de)
}

Received: 25 March 2013 - Published in Atmos. Chem. Phys. Discuss.: 26 April 2013

Revised: 30 August 2013 - Accepted: 8 October 2013 - Published: 13 November 2013

\begin{abstract}
During the field campaign ZEPTER-2 in autumn 2008 whole air samples were collected on board a Zeppelin NT airship in the planetary boundary layer (PBL) and the lower free troposphere (LFT) over south-west Germany using the ZEppelin Based Isotope Sampler (ZEBIS). These samples were analysed with respect to volatile organic compound (VOC) mixing ratios and stable carbon isotope ratios using a gas chromatograph combustion isotope ratio mass spectrometer (GC-C-IRMS). In this study we present results for toluene, one of the major anthropogenic pollutants, which emphasise the viability of isotope ratio measurements in VOC for atmospheric research, especially to study VOC sources or to track both dynamical and chemical processes. In situ measurements of $\mathrm{CO}$ mixing ratios on board the Zeppelin NT were used to allocate the air samples either to the PBL or the LFT.

In the PBL we observed rather fresh emissions mixing into the background air. We estimated a toluene source isotope ratio of $\delta^{13} \mathrm{C}=-28.2 \pm 0.5 \%$. Samples from the PBL and the LFT were clearly distinguishable by means of their mixing ratio and isotope ratio signatures. Using the concept of the effective kinetic isotope effect, we were able to separate the effects of dilution processes and photochemical degradation in the free troposphere. We calculated the photochemical age of toluene in the atmosphere in two different ways using isotope ratios and mixing ratios. The results differ strongly in the PBL, probably due to mixing processes, but are compatible with each other in the LFT. Here, they correlate with a slope of $0.90 \pm 0.31$.
\end{abstract}

\section{Introduction}

Despite their low concentrations volatile organic compounds (VOC) play an important role in atmospheric (especially tropospheric) chemistry. The majority of anthropogenic VOC emissions stems from fossil fuel use and is emitted predominantly during road transport and oil production. The most abundant species being emitted in this context, are toluene and benzene (e.g. Williams and Koppmann, 2007; Reimann and Lewis, 2007).

Rudolph et al. (1997) presented a method to determine stable carbon isotope ratios in VOC at ambient concentration levels using a gas chromatography combustion isotope ratio mass spectrometer (GC-C-IRMS). They proposed that measurements of the isotopic composition of VOC, beside measurements of their concentrations, would lead to valuable additional information on atmospheric processes (e.g. photochemical degradation). This initial methodology has been followed by a number of studies on this subject (see e.g. the review of Goldstein and Shaw, 2003, and references therein).

Stable carbon isotope ratios in VOC were measured in various regions, affected by different amounts of air pollution (Tsunogai et al., 1999; Rudolph et al., 2002; Redeker et al., 2007; Nara et al., 2007; Saito et al., 2009; Spahn, 2009). Rudolph et al. (2002) measured isotope ratios in atmospheric VOC close to their anthropogenic sources. Several laboratory studies investigated the kinetic isotope effects for reactions between VOC and different reactants (Anderson et al., 2003, 2004a, b; Iannone et al., 2008, 2009; Farkas et al., 2003; Rudolph et al., 2000) including the temperature dependence of the kinetic isotope effects (Anderson, 2005; Gensch et al., 2011). By applying the concept of the hydrocarbon clock on 
VOC isotopologues, stable carbon isotope ratios have also been used to determine the photochemical age of VOC in the atmosphere (Rudolph and Czuba, 2000; Rudolph et al., 2003; Saito et al., 2002, 2009).

\section{Theoretical background for the interpretation of isotope ratios}

All isotope ratios given in this paper are expressed in the $\delta$ notation, relative to the Vienna Pee Dee Belemnite (V-PDB) standard for stable carbon isotope analysis. The $\delta$ value is defined as the relative deviation from the standard's isotope ratio (Craig, 1957).

$$
\begin{aligned}
& \delta^{13} \mathrm{C}=\frac{\left({ }^{13} \mathrm{C} /{ }^{12} \mathrm{C}\right)_{\text {sample }}-\left({ }^{13} \mathrm{C} /{ }^{12} \mathrm{C}\right)_{\mathrm{V}-\mathrm{PDB}}}{\left({ }^{13} \mathrm{C} /{ }^{12} \mathrm{C}\right)_{\mathrm{V}-\mathrm{PDB}}} \times 1000 \% \\
& \left({ }^{13} \mathrm{C} /{ }^{12} \mathrm{C}\right)_{\mathrm{V} \text {-PDB }}=0.0112372
\end{aligned}
$$

A necessary requirement for the interpretation of isotope ratios is the knowledge of the kinetic isotope effect (KIE). The kinetic isotope effect, $\varepsilon$, describes, for a certain reaction, the relative difference between the rate coefficients, $k$, of two different isotopologues of the same compound. For example, the KIE (with respect to stable carbon isotopes) for the dominant reaction of toluene with $\mathrm{OH}$ is (Anderson, 2005)

$$
\begin{aligned}
\varepsilon_{\mathrm{OH}} & =\left(\frac{k_{\mathrm{OH}}\left({ }^{12} \mathrm{C}_{7} \mathrm{H}_{8}\right)}{k_{\mathrm{OH}}\left({ }^{13} \mathrm{C}^{12} \mathrm{C}_{6} \mathrm{H}_{8}\right)}-1\right) \times 1000 \% \\
& =5.95 \pm 0.28 \% 0 .
\end{aligned}
$$

Recently, Gensch et al. (2011) pointed out the relevance of the temperature dependence of the KIE for the interpretation of atmospheric measurements. We checked whether this effect has to be taken into account in the discussion of the results presented in this study. Therefore, we used laboratory measurements of KIE values for the reaction of toluene and $\mathrm{OH}$ at different temperatures presented by Anderson (2005), and extrapolated these down to $0^{\circ} \mathrm{C}$ (a conservative lower boundary for air temperatures during ZEPTER-2). We found that the $\varepsilon$ value at $0{ }^{\circ} \mathrm{C}$ differs from the value at room temperature by about $0.3 \%$, similar to the error of the $\varepsilon$ value. Thus, we conclude that the temperature dependence of the KIE, although generally important, can be neglected for the data discussed here.

In many atmospheric situations, an air parcel is affected not only by chemical reactions but also by dilution processes. The concept of the effective kinetic isotope effect $\varepsilon_{\text {eff }}$ includes both a chemical loss reaction (with $\mathrm{OH}$ in this case) with the kinetic isotope effect $\varepsilon_{\mathrm{OH}}$ and the time constant $\tau_{\mathrm{OH}}$ as well as a dilution process (by mixing with "zero" background air) with the time constant $\tau_{\text {dil }}$, which does not result in isotopic fractionation.

$\varepsilon_{\text {eff }}=\frac{\varepsilon_{\mathrm{OH}} / \tau_{\mathrm{OH}}}{1 / \tau_{\mathrm{OH}}+1 / \tau_{\mathrm{dil}}}$
For a substance emitted at time $t=0$ the following equation can be derived which relates the changes in the VOC mixing ratio $c$ to the changes in the isotope ratio $\delta$ (Rudolph, 2007).

$\delta(t)=\delta(0)-\varepsilon_{\mathrm{eff}} \ln \left(\frac{c(t)}{c(0)}\right)$

If air masses are mixed, which contain "fresher" and "aged" amounts of the same substance, respectively, Eq. (5) is invalid. In these cases, assuming that chemical processing can be neglected, the concept of two-endpoint mixing can be applied. We consider two mixing air masses, \#1 and \#2. If one air mass contains much larger VOC concentrations than the other $\left(c_{1} \gg c_{2}\right)$ and at the same time has a much smaller volume $\left(V_{1} \ll V_{2}\right)$, the resulting isotope ratio $\delta$ and the VOC concentration $c$ are linked to each other by the following equation (Rudolph, 2007):

$\delta=\delta_{1}+\frac{\left(\delta_{2}-\delta_{1}\right) c_{2}}{c}$.

The photochemical age (see Parrish et al., 1992) of a certain compound in an air mass is a measure for the degree of photochemical processing this compound has experienced since it has been released to the atmosphere. It is defined as

$[\mathrm{OH}]_{\mathrm{avg}} t=\int_{0}^{t}[\mathrm{OH}] \mathrm{d} t^{\prime}$

and can be derived from isotopic measurements (Rudolph and Czuba, 2000) via

$[\mathrm{OH}]_{\mathrm{avg}} t=\frac{\delta(t)-\delta(0)}{\varepsilon_{\mathrm{OH}} k_{\mathrm{OH}}}$.

Even in cases when air masses mix, which contain different "ages" of the same compound, Eq. (8) can be applied and gives a concentration-weighted mean photochemical age, provided that $\delta(0)$ is the same for both air masses (Rudolph and Czuba, 2000).

Also, if two compounds ( $a$ and $b$ ) with different reaction constants $\left(k_{\mathrm{OH} a}\right.$ and $\left.k_{\mathrm{OH} b}\right)$ are emitted from the same source in a certain known ratio $\left(c_{a}(0) / c_{b}(0)\right)$, their photochemical age can be calculated from their concentrations $\left(c_{a}(t)\right.$ and $\left.c_{b}(t)\right)$ at a given time $t$. This is the "conventional" way to calculate the photochemical age (see Roberts et al., 1984; Rudolph and Johnen, 1990; Parrish et al., 1992).

$[\mathrm{OH}]_{\mathrm{avg}} t=\frac{1}{k_{\mathrm{OH} b}-k_{\mathrm{OH} a}}\left(\ln \left(\frac{c_{a}(t)}{c_{b}(t)}\right)-\ln \left(\frac{c_{a}(0)}{c_{b}(0)}\right)\right)$

It should be mentioned, that photochemical ages derived from Eq. (9), may be strongly biased if air masses of different ages mix (see e.g. Rudolph and Johnen, 1990; McKeen et al., 1990, 1996; Rudolph and Czuba, 2000; Saito et al., 2009). 


\section{Experiment}

\subsection{Measurement campaign}

In autumn 2008, the ZEPTER-2 campaign took place in the Lake Constance region in south-west Germany, a rural site with small townships and no large industries.

A Zeppelin NT airship served as the measurement platform. ZEBIS was installed inside the gondola. Depending on the environmental conditions, the Zeppelin can reach a maximum height of about $3000 \mathrm{~m}$ above sea level and a maximum speed of about $115 \mathrm{kmh}^{-1}$. The maximum scientific payload is about 1t (ZLT Zeppelin Luftschifftechnik GmbH \& Co $\mathrm{KG})$. The Zeppelin was equipped with various instruments in different configurations, amongst others a vacuum ultraviolet resonance fluorescence instrument for the measurement of CO (for an instrument description see e.g. Gerbig et al., 1999; Holloway et al., 2000). In addition, meteorological parameters were measured (for more information about ZEPTER-2 and the Zeppelin NT see Häseler et al., 2009).

The airborne measurements were supported by groundbased measurements using a mobile laboratory (a modified van), equipped, amongst others, with a whole air sampler. These air samples were analysed offline using a GC-FID system to determine VOC mixing ratios at ground level (Urban, 2010).

In total, 25 flights were carried out on 14 days between 17 October 2008 and 8 November 2008 at different times of day (including the night), taking off from Friedrichshafen $\left(47^{\circ} 39^{\prime} \mathrm{N}, 9^{\circ} 28^{\prime} \mathrm{E}\right)$. The ZEBIS whole air sampler was operated during 11 flights between 25 October 2008 and 7 November 2008. The individual flights passed over several regions of different land use: Lake Constance, two forests (Altdorf forest and Tettnang forest), grassland and the city of Ravensburg. In this paper we present data of samples gathered during five flights (see Table 1). The corresponding flight tracks are shown in Fig. 1 and the flight altitude above ground level (AGL) is shown in Fig. 2. Air temperature, relative humidity, wind speed and wind direction are given in Table 2, as far as available.

\subsection{Whole air sampler}

Ambient whole air samples were collected using the ZEBIS (ZEppelin Based Isotope Sampler) instrument and afterwards analysed in the laboratory using a GC-C-IRMS system. ZEBIS consists of a swing piston compressor (NPK09 DC, KNF Neuberger), a custom-made electrical control unit and two canister modules, each containing four evacuated SilcoCan ${ }^{\mathrm{TM}}$ canisters (Restek GmbH, Bad Homburg, Germany) with a volume of $6 \mathrm{~L}$ (see Fig. 3).

The compressor is operated continuously during a flight. At times when no canister is being pressurised, the exhaust valve at the end of the sample line is opened and the compressor provides a flow of $\sim 8 \mathrm{Ln} \mathrm{min}^{-1}$, thus flushing the sys-

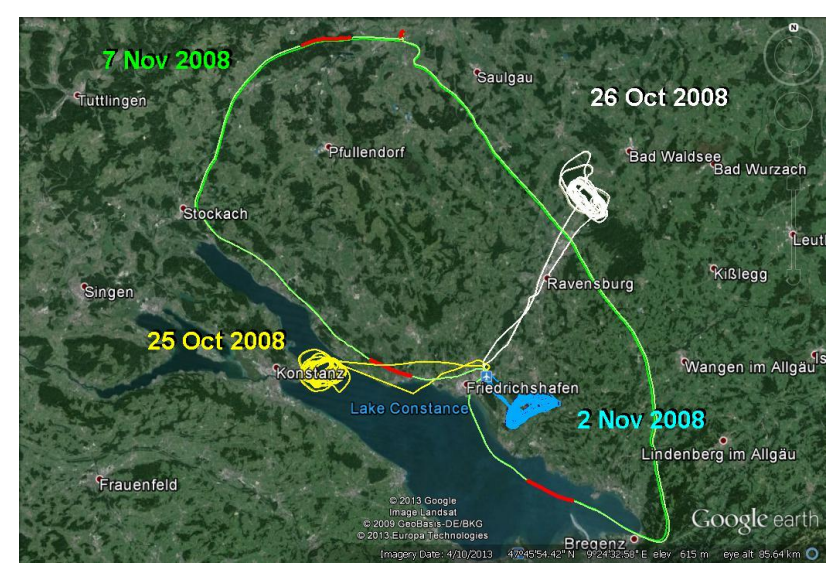

Fig. 1. Tracks of the five flights during which the whole air samples were collected; in the flight track of 7 November 2008 the sampling times are marked in red.
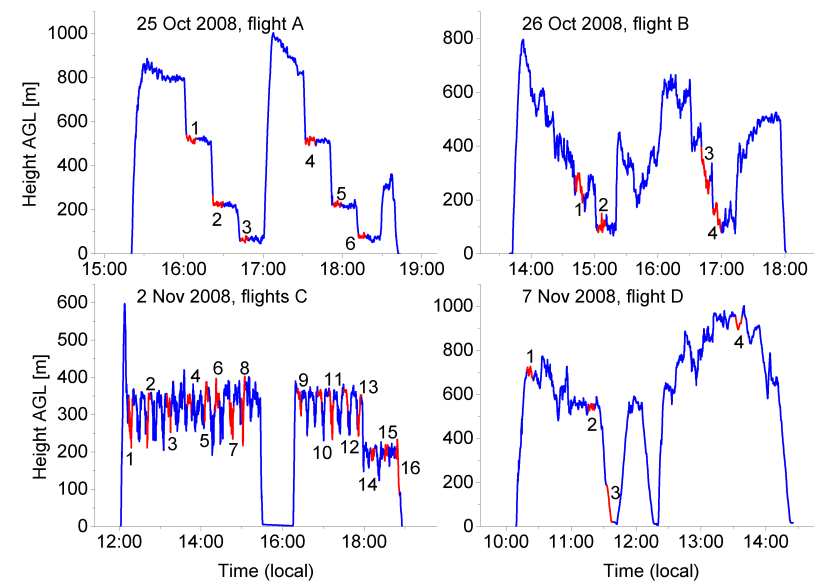

Fig. 2. Flight altitude above ground level versus local time; the sampling times are marked in red and numbered in chronological order.

tem. Each canister is locked by a normally closed solenoid valve (Clippard Europe, S.A., Louvain-la-Neuve, Belgium), which can be switched both manually or automatically. To fill a certain canister, the corresponding solenoid valve is opened and the exhaust valve at the end of the sample line is closed simultaneously. When a pressure of $4 \mathrm{bar}$ is reached, both valves are switched again, thereby closing the canister and allowing the sample line to be flushed. During ZEPTER-2 it took $\sim 3-5$ min to fill one canister, depending on the flight level.

The samples were taken from the meteorology mast in front of the Zeppelin NT gondola using a $10 \mathrm{~m}$ inlet line (1/4" FEP tubing, $3 \mathrm{~mm}$ ID, Bohlender GmbH, Grünsfeld, Germany). Particles, $\mathrm{OH}$, ozone, $\mathrm{H}_{2} \mathrm{O}$ and $\mathrm{CO}_{2}$ might corrupt the measurements of carbon isotopes in VOC. The inlet was equipped with a particle filter (Bohlender $\mathrm{GmbH}$ ) that removes particles larger than $10 \mu \mathrm{m}$. $\mathrm{OH}$ radicals are destroyed 
Table 1. Overview of the analysed flights.

\begin{tabular}{llclll}
\hline & Date & MEZ & Flight area & & Flight profile \\
\hline A & 25 Oct 2008 & $14: 25-17: 40$ & Lake Constance & $47^{\circ} 40^{\prime} \mathrm{N}, 9^{\circ} 11^{\prime} \mathrm{E}$ & vertical profile \\
B & 26 Oct 2008 & $12: 45-16: 45$ & Altdorf forest & $47^{\circ} 51^{\prime} \mathrm{N}, 9^{\circ} 41^{\prime} \mathrm{E}$ & vertical profile \\
C & 2 Nov 2008 & $12: 00-15: 30$ & Tettnang forest & $47^{\circ} 38^{\prime} \mathrm{N}, 9^{\circ} 34^{\prime} \mathrm{E}$ & constant altitude \\
C & 2 Nov 2008 & $16: 10-19: 00$ & Tettnang forest & $47^{\circ} 38^{\prime} \mathrm{N}, 9^{\circ} 34^{\prime} \mathrm{E}$ & constant altitude \\
D & 7 Nov 2008 & $10: 05-14: 25$ & Large scale & $48^{\circ} 3^{\prime} \mathrm{N}-47^{\circ} 29^{\prime} \mathrm{N}, 9^{\circ} 1^{\prime} \mathrm{E}-9^{\circ} 48^{\prime} \mathrm{E}$ & constant altitude \\
\hline
\end{tabular}

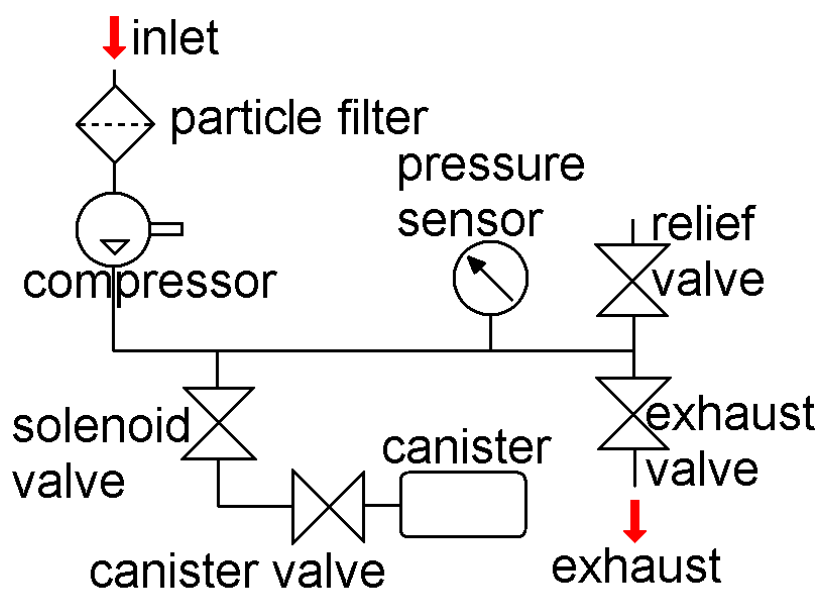

Fig. 3. Gas flow system of the whole air sampler ZEBIS; one canister is shown as an example, the total number of canisters is eight.

by collision with the line wall. A special ozone-removing device did not seem to be necessary, since the reactions between the aromatic hydrocarbons of interest and ozone are negligible: the reaction constant for the reaction between ozone and toluene is $(1.5 \pm 0.8) \times 10^{-23} \mathrm{~cm}^{3}$ molecule ${ }^{-1} \mathrm{~s}^{-1}$ and for the reaction between ozone and benzene $(7 \pm 4) \times$ $10^{-23} \mathrm{~cm}^{3}$ molecule ${ }^{-1} \mathrm{~s}^{-1}$ (Atkinson and Lloyd, 1984). $\mathrm{H}_{2} \mathrm{O}$ is removed in the laboratory system prior to analysis, $\mathrm{CO}_{2}$ is separated chromatographically from the VOC sample (see Sect. 3.3).

\subsection{Laboratory system}

The air samples were analysed using a commercial GC-CIRMS, consisting of (i) a thermal desorption system (TDS) with water traps for sample preparation, combined with a cold injection system (CIS) to focus and transfer the sample to the gas chromatograph; (ii) a gas chromatograph (GC), equipped with a cold trapping system (CTS) to cryo-focus the sample at the beginning of the column; (iii) a combustion furnace to oxidise the VOC to $\mathrm{CO}_{2}$ and $\mathrm{H}_{2} \mathrm{O}$, followed by a water trap to remove the produced $\mathrm{H}_{2} \mathrm{O}$; and (iv) an isotope ratio mass spectrometer (IRMS) to determine the ${ }^{13} \mathrm{C} /{ }^{12} \mathrm{C}$ ratios of the individual VOC. The GC-C-IRMS used in this study is very similar to the system described by Iannone et al.
Table 2. Basic meteorological metadata for the samples discussed in this paper; the data represent averages of the corresponding variables over the sampling time.

\begin{tabular}{|c|c|c|c|c|}
\hline Sample & $\begin{array}{r}\text { Temperature } \\
\left({ }^{\circ} \mathrm{C}\right)\end{array}$ & $\begin{array}{r}\text { Relative } \\
\text { humidity }(\%)\end{array}$ & $\begin{array}{r}\text { Wind } \\
\text { speed }\left(\mathrm{ms}^{-1}\right)\end{array}$ & $\begin{array}{r}\text { Wind } \\
\text { direction }\left({ }^{\circ}\right)\end{array}$ \\
\hline A1 & 6.8 & 71 & 6.7 & 33 \\
\hline A2 & 6.8 & 94 & 2.1 & 16 \\
\hline A3 & 8.2 & 89 & 2.6 & 39 \\
\hline A4 & 6.5 & 84 & 4.0 & 35 \\
\hline A5 & 6.9 & 92 & 1.8 & 309 \\
\hline A6 & 7.7 & 91 & 1.8 & 287 \\
\hline B1 & 8.1 & 86 & 4.5 & 232 \\
\hline B2 & 10.4 & 50 & 8.2 & 247 \\
\hline B3 & 11.7 & 54 & 9.9 & 226 \\
\hline B4 & 10.9 & 64 & 7.8 & 263 \\
\hline $\mathrm{C} 1$ & 13.5 & 58 & 7.8 & 81 \\
\hline $\mathrm{C} 2$ & 13.8 & 53 & 5.6 & 124 \\
\hline C3 & 13.9 & 52 & 6.4 & 119 \\
\hline $\mathrm{C} 4$ & 13.9 & 52 & 5.1 & 114 \\
\hline $\mathrm{C} 5$ & 14.5 & 50 & 4.8 & 115 \\
\hline C6 & 14.0 & 56 & 7.6 & 100 \\
\hline $\mathrm{C} 7$ & 15.4 & 48 & 5.8 & 119 \\
\hline $\mathrm{C} 8$ & 15.7 & 47 & 7.4 & 115 \\
\hline C9 & 15.8 & 49 & 6.3 & 109 \\
\hline $\mathrm{C} 10$ & 16.0 & 48 & 5.9 & 109 \\
\hline $\mathrm{C} 11$ & 16.2 & 48 & 5.3 & 113 \\
\hline $\mathrm{C} 12$ & 16.3 & 47 & 6.0 & 86 \\
\hline $\mathrm{C} 13$ & 16.5 & 44 & 7.4 & 123 \\
\hline C14 & 11.8 & 85 & 5.3 & 64 \\
\hline $\mathrm{C} 15$ & 11.1 & 89 & 4.4 & 72 \\
\hline C16 & 11.1 & 83 & 6.0 & 60 \\
\hline D1 & 5.5 & 85 & 4.1 & 268 \\
\hline D2 & 6.3 & 79 & 3.7 & 292 \\
\hline D3 & 11.3 & 84 & & \\
\hline D4 & 5.0 & 78 & 2.9 & 262 \\
\hline
\end{tabular}

(2007). Therefore, the individual parts of the system are described only briefly here.

The TDS (TDSG Large, Gerstel GmbH\&Co. KG, Mühlheim a.d. Ruhr, Germany) is used to cryogenically extract the VOC from the whole air sample, to remove the sample humidity and to determine the sample volume. The flow rate during preconcentration was set to $1 \mathrm{Lnmin}^{-1}$. The water traps are Silcosteel ${ }^{\mathrm{TM}}$ treated (Restek $\mathrm{GmbH}$, Bad Homburg, Germany) stainless steel tubes operated at 
a temperature of $-20^{\circ} \mathrm{C}$. The preconcentration trap is packed with glass beads (mesh 60/80) and is operated at $-150^{\circ} \mathrm{C}$. For desorption the trap is heated to $230^{\circ} \mathrm{C}$ at a rate of $40^{\circ} \mathrm{Cmin}^{-1}$. Following the desorption the VOC sample is dried in two additional water traps, which are also operated at a temperature of $-20^{\circ} \mathrm{C}$. Finally, the VOC are cryo-focussed again in the CIS at a temperature of $-150^{\circ} \mathrm{C}$.

The CIS (KAS 4, Gerstel GmbH\&Co. KG) is a glass tube packed with glass beads (mesh 80/100). For desorption of the sample the CIS is heated to $250^{\circ} \mathrm{C}$ at a rate of $12^{\circ} \mathrm{Cs}^{-1}$.

The VOC are separated from each other and also from the ambient $\mathrm{CO}_{2}$ by gas chromatography. VOC separated on a non-polar J\&W DB-5 ms column $(30 \mathrm{~m} \times 0.5 \mu \mathrm{m}$ film $\times$ $0.32 \mathrm{~mm}$ ID) are transferred to a low polar J\&W DB-624 column $(30 \mathrm{~m} \times 1.8 \mu \mathrm{m}$ film $\times 0.32 \mathrm{~mm}$ ID) for additional separation during a single measurement. Prior to compound separation, the VOC sample is cryo-focussed once again in the CTS (Gerstel GmbH\&Co. KG). During focussing the CTS is kept at $-150^{\circ} \mathrm{C}$, during desorption the CTS is heated to $250^{\circ} \mathrm{C}$ at a rate of $12^{\circ} \mathrm{Cs}^{-1}$.

The GC temperature programme starts with a $4 \mathrm{~min}$ isothermal phase at $-20^{\circ} \mathrm{C}$ followed by a temperature ramp of $4^{\circ} \mathrm{Cmin}^{-1}$ to $200^{\circ} \mathrm{C}$, followed by a ramp of $10^{\circ} \mathrm{Cmin}^{-1}$ to $250^{\circ} \mathrm{C}$, and is then held isothermal for $10 \mathrm{~min}$. The average flow velocity of the He carrier gas is set to $40 \mathrm{~cm} \mathrm{~s}^{-1}$.

After separation, the VOC eluting from the GC flow through a commercially available combustion interface (Model GC5-MK1, GV Instruments Ltd., Manchester, UK), where they are oxidised quantitatively to $\mathrm{CO}_{2}$ and $\mathrm{H}_{2} \mathrm{O}$. The combustion interface consists of a quartz tube partially situated in a heated zone of $350^{\circ} \mathrm{C}$ and, further downstream, within a furnace kept at $850^{\circ} \mathrm{C}$. The part of the quartz tube within the combustion furnace, where the oxidation takes place, is packed with $\mathrm{CuO}$ pellets (size $0.1-0.5 \mathrm{~mm}$ ), which provide the oxygen necessary for the reaction. The gas flow then passes through a cold trap where water generated during the combustion process is removed. The cold trap consists of a coiled capillary, kept at $-100^{\circ} \mathrm{C}$, as suggested by Leckrone and Hayes (1998).

The $\mathrm{CO}_{2}$ is transferred to the source of an Isoprime IRMS (GV Instruments Ltd., Manchester, UK) through an open split. The three ion beams comprising $m / z, 44,45$ and 46 are detected by Faraday cup collectors.

At the beginning and the end of each measurement run, pulses of a certified $\mathrm{CO}_{2}$ reference standard gas (Air Liquide Deutschland GmbH, Düsseldorf, Germany) are introduced as a calibration gas. The $\delta^{13} \mathrm{C}$ value of the standard gas is $-25.80 \pm 0.2 \%$.

Data processing (e.g. peak integration, calibration, correction according to Santrock et al., 1985) is accomplished using the Continuous Flow Data Processing software (GV Instruments Ltd.).

\subsubsection{Calibration and characterisation procedure}

A custom-made dynamic gas dilution system (for details see Hembeck, 2008) was used to dilute VOC gas standards at ppm levels with dry or humidified $\mathrm{N}_{2}$ to produce working standards with different VOC volume mixing ratios (VMR) at typical ambient levels (ranging from $\sim 100 \mathrm{ppt}$ to some ppb in the case of toluene and benzene) and with different humidities. These standard dilutions were used to calibrate and characterise the GC-C-IRMS system.

A stable mixture of VOC in air (hereafter referred to as "standard A"), diluted down to typical atmospheric volume mixing ratios $(0.7 \mathrm{ppb}$ of benzene and $0.2 \mathrm{ppb}$ of toluene), was measured every day during the canister measurements to determine the reproducibility of the measurements (major ion peak areas, isotope ratios) and to identify possible drifts (see Sect. 3.3.5).

After the campaign, a series of measurements of an eightcomponent working standard (hereafter referred to as "standard B") with known VOC volume mixing ratios (184 $\pm 5 \mathrm{ppb}$ of toluene and $335 \pm 4 \mathrm{ppb}$ of benzene) was performed under various conditions (concerning dilution and humidity) to check the linearity of the system and to calibrate the detector's response (major ion peak areas) on VOC mixing ratios (see Sect. 3.3.3) as well as to investigate the impact of sample humidity on both major ion $(\mathrm{m} / \mathrm{z} 44)$ peak areas and isotope ratios (see Sect. 3.3.4).

\subsubsection{Accuracy of the isotope ratios}

The IRMS is calibrated during every run with ten peaks of a certified $\mathrm{CO}_{2}$ reference gas (see Sect. 3.3). The error of the mean of the measured isotope ratios for these ten reference gas peaks (expressed as a $\delta^{13} \mathrm{C}$ value) was always smaller than $0.1 \%$, the uncertainty of the reference gas $\delta^{13} \mathrm{C}$ value is specified to be $0.2 \%$. Combining these two errors, we estimate the accuracy of the IRMS $\delta^{13} \mathrm{C}$ measurements to be $0.22 \%$.

It is important to mention, that this is only the accuracy of the last step of the analysis, the isotope ratio measurement of the $\mathrm{CO}_{2}$ gas that reaches the IRMS. During other steps of the analysis, for example during the sample enrichment, some isotopic fractionation may occur. To estimate the accuracy of the measurement process in whole, a VOC standard gas with known VOC $\delta^{13} \mathrm{C}$ values would be required. Such a standard gas was not available during the measurements reported in this paper, therefore there might be an additional error in the absolute $\delta^{13} \mathrm{C}$ values.

\subsubsection{Detector response and linearity}

Since the present study focusses on toluene and benzene, only the calibration of these compounds will be presented here. Sixteen measurements of the diluted standard B at three different levels of VOC volume mixing ratios $(0.3-1.3 \mathrm{ppb}$ of 


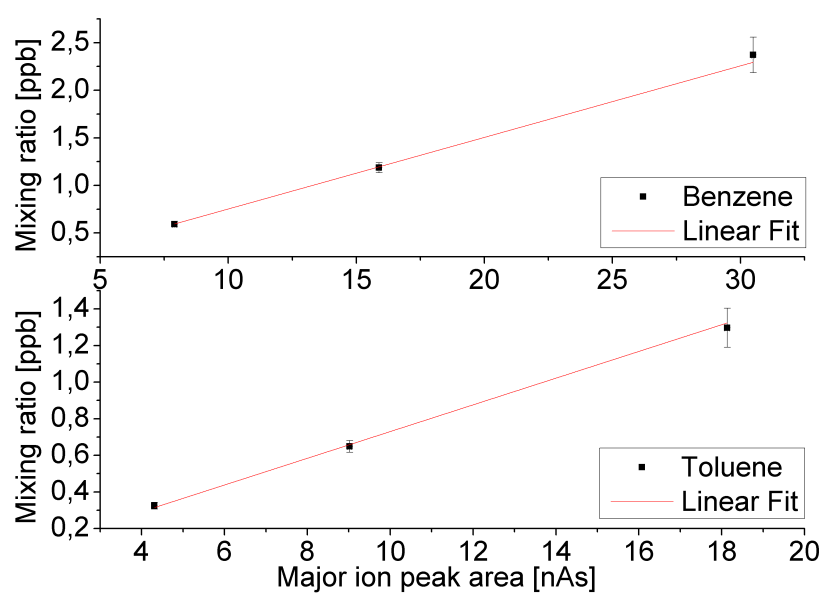

Fig. 4. VOC mixing ratios versus detector response for three dilution steps of standard B; each data point is the average of four to six measurements. The error bars of the VMR reflect the uncertainty of standard B's composition as well as the uncertainty of the dilution process, the error bars of the average peak areas represent the standard errors. Most error bars are smaller than the symbol size.

toluene and 0.6-2.4 ppb of benzene) and at a constant relative humidity of $\sim 50 \%$ were taken into account for the calibration.

The sample volume was $25 \mathrm{Ln}$ for all standard measurements. We found response curves of the type $y(x)=$ ax (Pearson $R>0.999$ ) for both compounds (see Fig. 4) for peak areas ranging from $7.9 \mathrm{nAs}(4.3 \mathrm{nAs})$ to $30.5 \mathrm{nAs}$ (18.1 nAs) in the case of benzene (toluene). Since the response curves show neither curvature nor offset over these ranges of peak areas, we extrapolated the response curves down to 0 nAs. Then, the corresponding VMR can be calculated for all benzene (toluene) peak areas, less than $30.5 \mathrm{nAs}$ $(18.1 \mathrm{nAs})$ via:

$\mathrm{VMR}=\frac{a \times \text { peak area } \times 25 \mathrm{Ln}}{\text { sample volume }}$

with $a=75.2 \pm 0.7 \mathrm{ppt} / \mathrm{nAs}(a=73.0 \pm 1.2 \mathrm{ppt} / \mathrm{nAs})$. All ZEPTER-2 peak areas are well below these upper limits.

Also, it was checked whether the $\delta^{13} \mathrm{C}$ values depend on the peak size. Figure 5 shows the averaged isotope ratios of toluene versus the averaged major ion $(m / z 44)$ peak areas for the three dilution steps, the error bars represent the corresponding standard deviations. The peak areas range from $4.3 \mathrm{nAs}$ to $18.1 \mathrm{nAs}$. A constant fit $y(x)=c$ was applied to the data. All $\delta^{13} \mathrm{C}$ values agree well with each other within the range of their standard deviations. To fill the gap below $4.3 \mathrm{nAs}$, we use data from calibration measurements that were carried out during another field campaign in 2010 using the same laboratory system as for the ZEPTER-2 measurements (Linke, 2012). Between the two campaigns, the GC columns were changed and an additional MS for compound identification was integrated, but these changes should

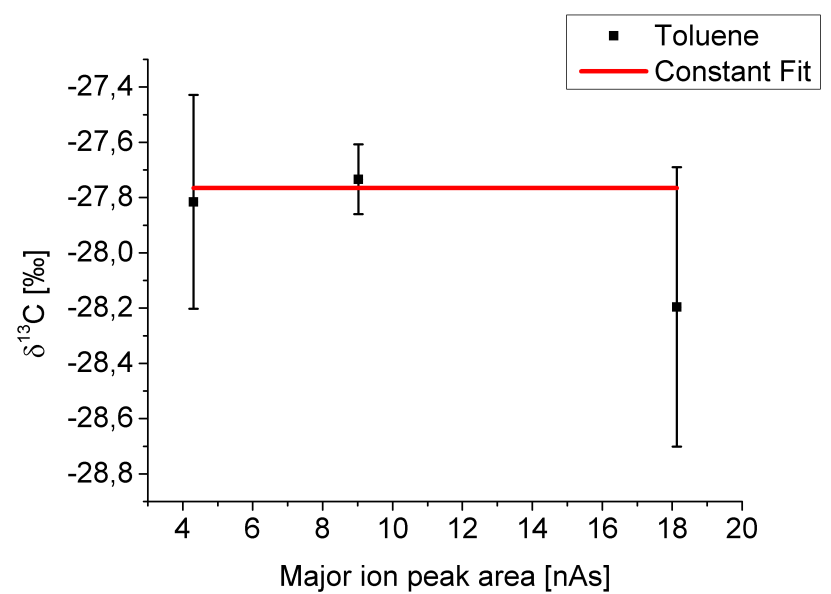

Fig. 5. Isotope ratios of benzene and toluene versus major ion peak areas for three dilution steps of standard B; each data point is an average of four to six measurements. The error bars of the isotope ratios represent the standard deviations. Error bars of the peak area are not shown, since they are not relevant for the constant fit.

not affect the isotope ratios of well-separated peaks like the toluene peak. We found no systematic increase or decrease for 41 dilutions of a stable VOC mixture with toluene peak areas ranging from $0.5 \mathrm{nAs}$ to $6 \mathrm{nAs}$. A linear fit applied to the data yields a slope of $0.19 \pm 1.04 \% \mathrm{nAs}^{-1}$. Therefore, we assume, that the isotope ratios do not depend on the peak size for toluene peak areas between $0.5 \mathrm{nAs}$ and $18.1 \mathrm{nAs}$.

\subsubsection{Influence of sample humidity}

If water is not removed from the sample prior to the GCC-IRMS measurements, it is known to cause a number of problems. It may influence the cryo-enrichment of VOC and thereby the peak areas. It may disturb the gas chromatography which results in unstable retention times. Additionally, if water molecules reach the IRMS, they may form ${ }^{1} \mathrm{H}^{12} \mathrm{C}^{16} \mathrm{O}_{2}^{+}$ ions which have the same mass as ${ }^{13} \mathrm{C}^{16} \mathrm{O}_{2}^{+}$ions and therefore corrupt the isotope ratio measurements (see Leckrone and Hayes, 1998).

To determine the effectivity of the water traps in use and to estimate the impact of the residual water in the sample, 23 measurements of humidified dilutions of standard B were carried out. The VOC volume mixing ratios were kept constant (2.9ppb of benzene and $1.6 \mathrm{ppb}$ of toluene), the relative humidity (RH) level was varied in five steps between $16 \%$ and $80 \%$. The sample humidity is hard to control with the gas dilution system and changes during sample enrichment, we estimate the error of the sample humidity to be $\sim 5 \% \mathrm{RH}$.

We found the peak areas to increase with increasing sample humidity (see Fig. 6). For toluene, the peak area changes by less than $7 \%$ over the whole humidity range, for benzene the effect is even smaller. Since the VMR calibration (see Sect. 3.3.3) was carried out with standard B dilutions 


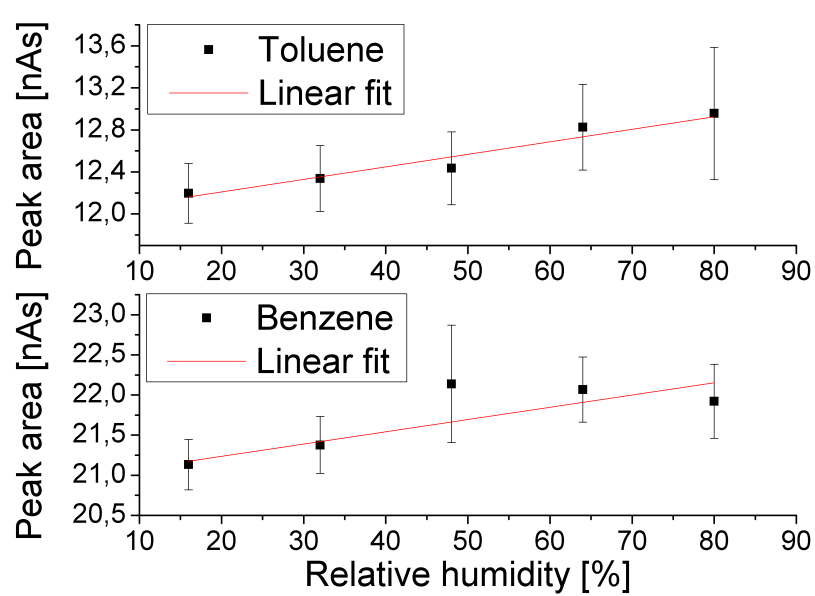

Fig. 6. Averaged major ion peak areas of benzene and toluene for dilutions of standard B at different sample humidities; the error bars represent the standard deviations of the peak areas. The uncertainty of the humidity values is roughly $5 \% \mathrm{RH}$ (see text). We find a small but nevertheless significant systematic increase of the peak areas with increasing humidity.

containing $50 \% \mathrm{RH}$, we estimate $3.5 \%$ to be the upper limit for the humidity-induced error of the measured peak areas. This worst-case estimation is also valid for the ZEPTER-2 samples.

Figure 7 shows averaged $\delta^{13} \mathrm{C}$ values for the five different sample RH levels mentioned above and also for dry samples. No systematic drift can be seen in the data, also the values for dry samples agree well with all the other values. We therefore conclude, that the isotope ratio measurements are not corrupted by the sample humidity.

\subsubsection{Precision of the results}

Eleven measurements of standard A were used to determine the precision of the peak areas and the $\delta^{13} \mathrm{C}$ values during the campaign. Since the precisions are generally expected to depend on the peak size, we selected five well-separated peaks of different sizes (including the benzene and toluene peaks), calculated the standard deviations of the peak areas $\sigma_{A}$ and the $\delta^{13} \mathrm{C}$ values $\sigma_{\delta}$ and plotted these standard deviations versus the mean peak areas $A$. We estimated the uncertainties of the standard deviations via

$\Delta \sigma=\frac{\sigma}{\sqrt{2 n}}$

where $n$ is the number of measurements.

Figure 8 shows $\sigma_{A}$ plotted versus $A$, both given in nAs. We applied a linear fit (Pearson $R=0.81$ ) to the data and derived the following function

$\sigma_{A}=0.06 \mathrm{nAs}+1.3 \% \times A$

which was later used to estimate the precision of the ZEPTER-2 peak areas.

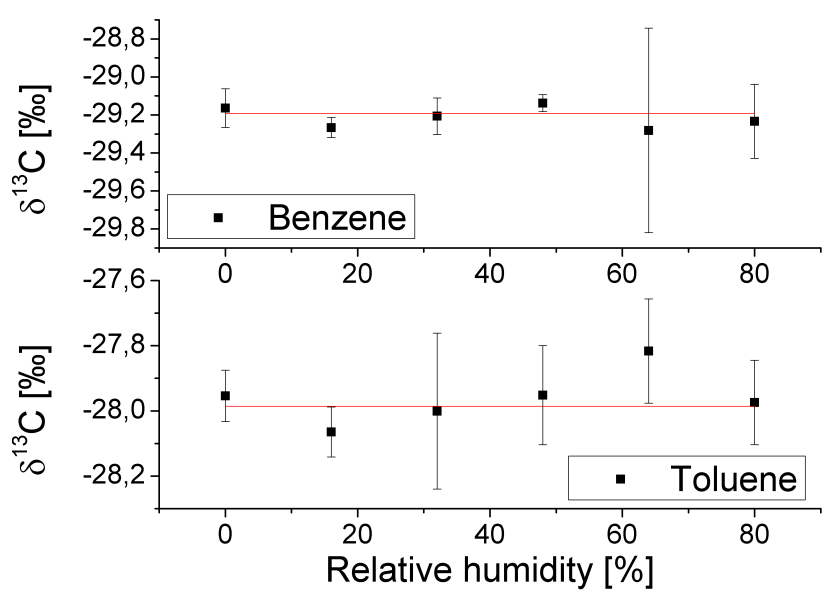

Fig. 7. Averaged isotope ratios for dilutions of standard B at different sample humidities; the error bars represent the standard deviations. A constant fit (red line) is applied. Error bars for the sample humidity are not shown since they do not influence the constant fit.

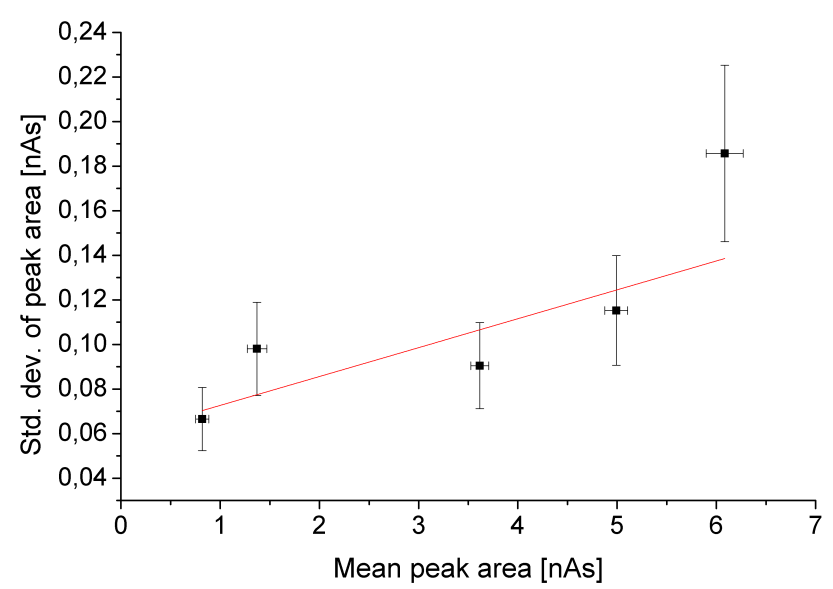

Fig. 8. Standard deviations of the peak area versus the mean peak area for five peaks of different sizes, based on measurements of standard A; the error bars represent the uncertainties of the standard deviation (see text). A linear fit (red line) is applied to the data.

The precision $\sigma_{\delta}$ of the measured isotope ratios $\delta$ naturally depends on the amount of carbon available for the isotope analysis (i.e. the peak size). Based on counting statistics, one would expect a dependency of the following form (see Brand, 2004, and the references therein):

$\sigma_{\delta} \propto \frac{1}{\sqrt{A}}$.

Figure 9 shows $\sigma_{\delta}$ (in \%o) plotted versus $A$ (in nAs). Fitting a function of the form

$y(x)=a x^{b}$

to the data yields an exponent of $b=-0.6 \pm 0.2$, which is in agreement with the theory, i.e. Eq. (13). Therefore we 


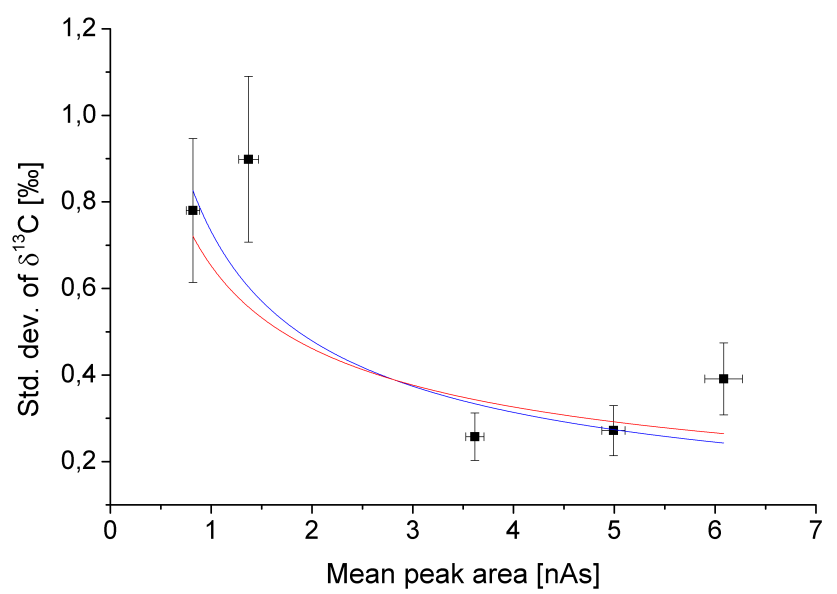

Fig. 9. Standard deviations of the $\delta^{13} \mathrm{C}$ values versus the mean peak areas for five peaks of different sizes, based on measurements of standard A; the error bars represent the uncertainties of the standard deviations (see text). Two power function-fits are applied to the data: with a free exponent (blue line) and with an exponent fixed to -0.5 (red line, for details see text).

fixed the exponent $b$ to the theoretical value of $b=-0.5$ and repeated the fitting process. Thereby we derived a parameter value of $a=0.65 \pm 0.09 \%$ o $\sqrt{\mathrm{nAs}}$ and thus the following function to estimate the precision of the ZEPTER-2 isotope ratios:

$\sigma_{\delta}=\frac{0.65 \% \circ}{\sqrt{A / 1 \mathrm{nAs}}}$.

This estimation is only reliable for the peak area range covered by the tests. Therefore, only measurements with a peak area of $0.8 \mathrm{nAs}$ or larger are presented and discussed in the following.

\section{Results}

Unfortunately, we found the benzene peak to overlap with a much smaller peak of a so far unidentified substance in the ZEPTER-2 chromatograms (see Fig.10). It turned out, that this peak overlap corrupts the measured $\delta^{13} \mathrm{C}$ values of benzene, so we do not use them in the discussion. However, the effect on the benzene VMR is small. A very conservative estimation, based on the maximum peak size of the small peak, yields a maximum error induced on the benzene peak areas of $0.2 \mathrm{nAs}$.

For every flight presented, we determined the height of the planetary boundary layer (PBL) based on in situ CO measurements with a time resolution of $1 \mathrm{~s}$. Figure 11 shows the vertical profiles of the $\mathrm{CO}$ mixing ratios for the five flights. Each profile shows high $\mathrm{CO}$ mixing ratios directly above the ground up to a few hundred meters. This height regime is interpreted as the well-mixed PBL. Above the PBL a very

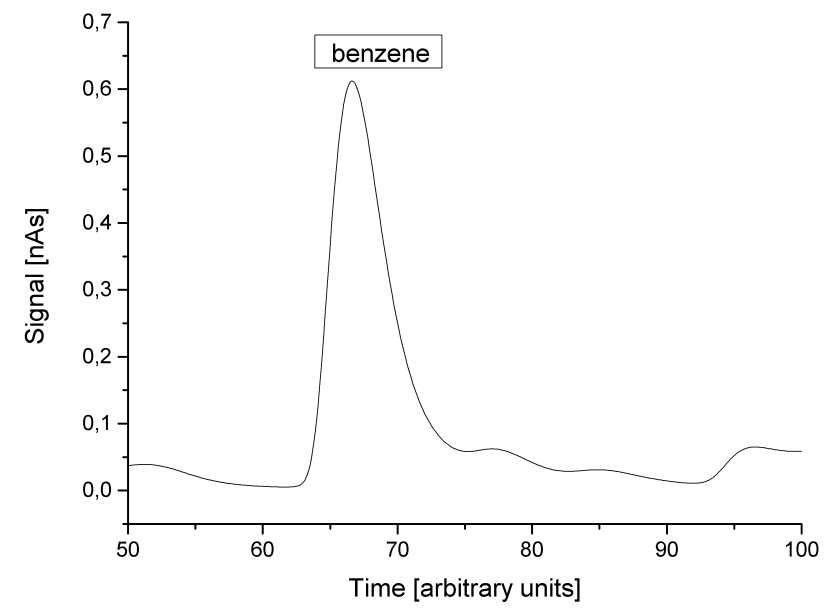

Fig. 10. Part of a sample chromatogram, showing the peak overlap between benzene and another so far unidentified compound.
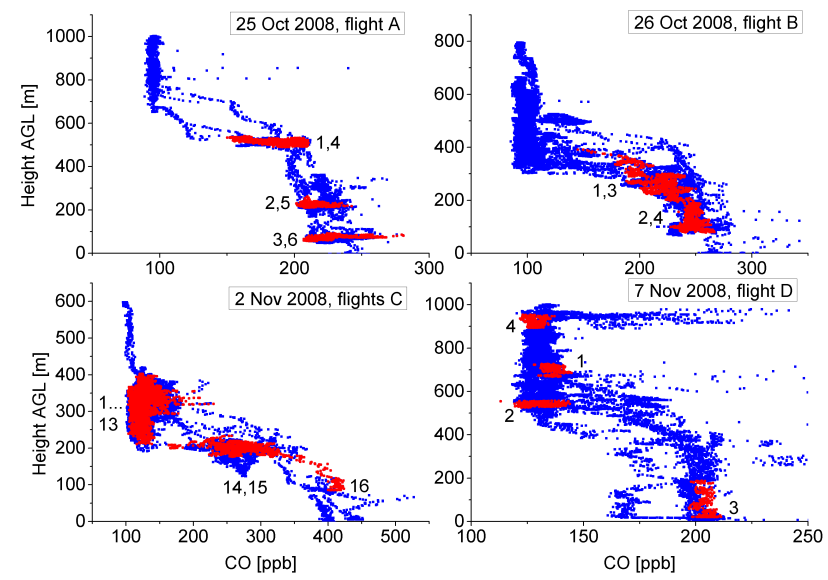

Fig. 11. Vertical profiles of $\mathrm{CO}$ mixing ratios, visualising the height of the PBL; the time resolution is $1 \mathrm{~s}$. Data points from time periods during which canisters were filled, are marked in red. The canisters are numbered in chronological order.

sharp decrease of the $\mathrm{CO}$ mixing ratio can be seen, marking the transition from the PBL to the lower free troposphere (LFT), followed by the LFT, where CO mixing ratios are relatively constant.

Three samples were excluded from the analysis and do not appear in the figures: (i) two, because the $\mathrm{CO}$ data show spike-like structures during the sampling times and therefore the samples are suspected to represent self-matches of the Zeppelin NT and (ii) one which we regard as an outlier because its toluene $\delta^{13} \mathrm{C}$ value is about $3 \%$ higher than those of the neighbouring data points from the same flight, although the VMR are almost the same. The remaining number of samples is 30, 14 taken in the PBL and 16 in the LFT.

The histogram in Fig. 12 gives an overview of the toluene isotope ratios measured during ZEPTER-2. The mean error 


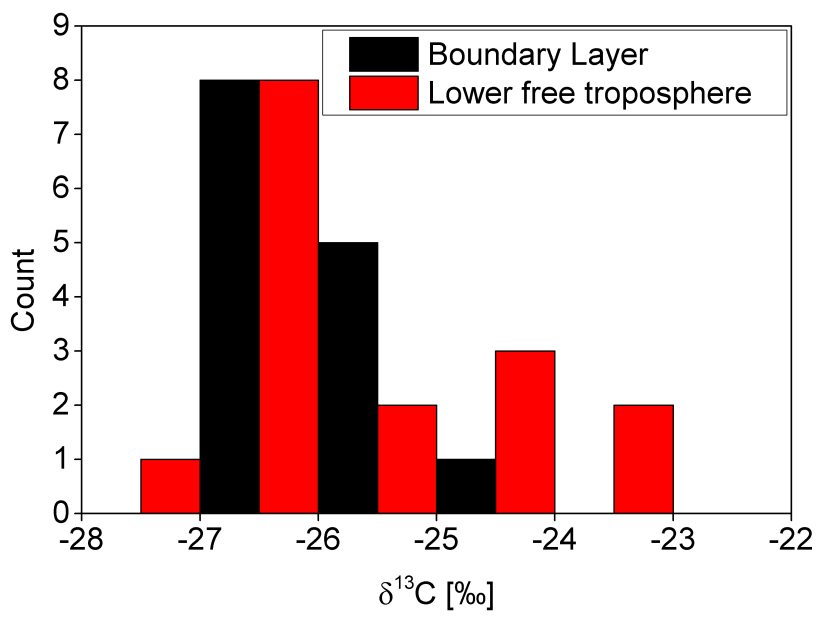

Fig. 12. Histogram of all toluene $\delta^{13} \mathrm{C}$ values measured during ZEPTER-2; the mean error is $0.53 \%$ o (i.e. half the bin width).

of the $\delta^{13} \mathrm{C}$ values is $0.53 \%$. The distributions are strongly asymmetric, indicating that photochemical processes took place in the air mass history. The most frequent $\delta^{13} \mathrm{C}$ values of the distributions (between $-27 \%$ and $-26 \%$ ) are in the vicinity of source values reported in the literaturee: $-26.5 \%$ o (v. Czapiewski et al., 2002), between $-28.4 \%$ and $-27.1 \%$ o (Rudolph et al., 2002), $-26.1 \%$ and $-27.2 \%$ (Thompson, 2003). As expected, we find higher $\delta^{13} \mathrm{C}$ values in the LFT than in the PBL, since higher $\delta^{13} \mathrm{C}$ values correspond to "older" air masses.

The observed VMR range from 88 to $688 \mathrm{ppt}$ in the case of toluene and from 153 to $731 \mathrm{ppt}$ in the case of benzene.

The Figs. 13 and 14 show all measured toluene VMR and $\delta^{13} \mathrm{C}$ values, respectively, together with the corresponding height of the air samples.

\section{Discussion}

In the analysis of the ZEPTER-2 data several linear fits were applied. For this purpose, we used a fitting procedure based on the work of Fasano and Vio (1988), to account for the errors on both coordinates.

\section{$5.1 \quad \delta^{13} \mathrm{C}$ source value}

In the data gathered on 25 October 2008, both VMR and $\delta^{13} \mathrm{C}$ values of toluene show a pronounced vertical profile in the PBL (see Fig. 13 and Fig. 14). The $\delta^{13} \mathrm{C}$ source value of toluene can be estimated by making the assumption that we observed fresh emissions from the ground mixing into the PBL background air without significant photochemical processing. In this case we can use the concept of two-endpointmixing (see Sect. 2). Figure 15 shows the toluene $\delta^{13} \mathrm{C}$ values versus the inverse VMR. A linear fit yields a toluene $\delta^{13} \mathrm{C}$ source value of $\delta_{0}=-28.2 \pm 0.5 \%$. Since this delta

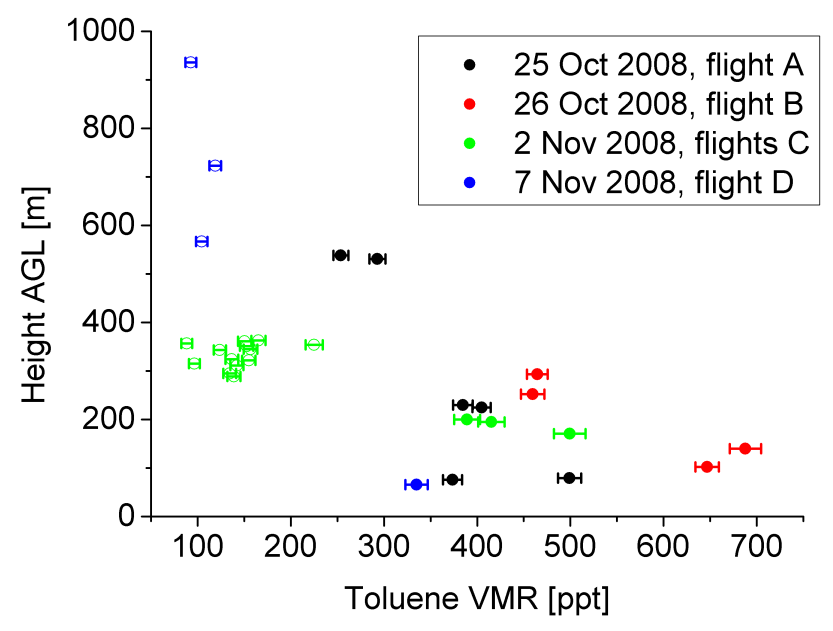

Fig. 13. Vertical profiles (height above ground level) of toluene VMR; data from the PBL are shown as filled circles, data from the LFT as open circles.

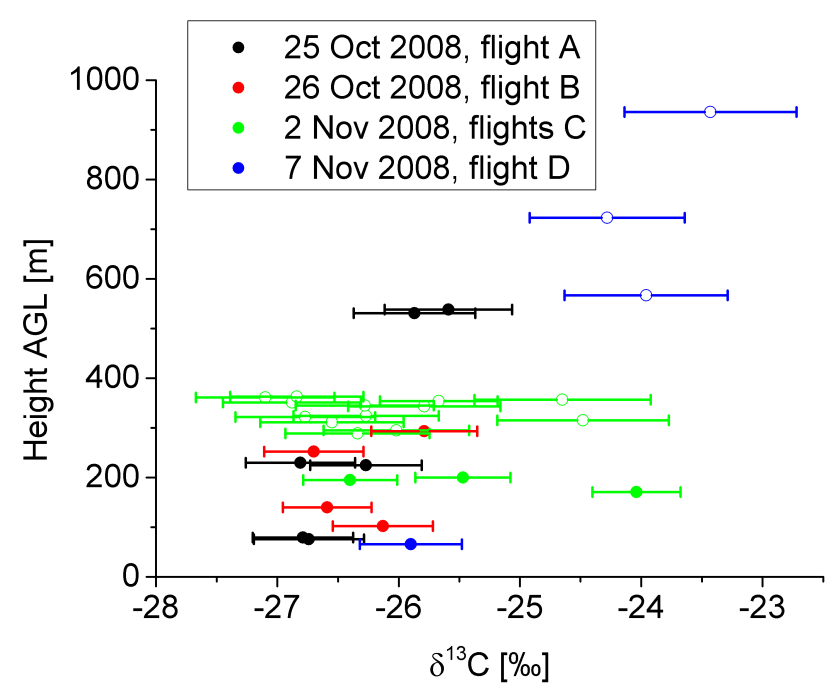

Fig. 14. Vertical profiles (height above ground level) of toluene $\delta^{13} \mathrm{C}$ values; data from the PBL are shown as filled circles, data from the LFT as open circles.

source value is in the range of previous reports (see Sect. 4), the assumption of predominant mixing seems to be justified. Nevertheless, the value might be slightly biased due to photochemical processing, which might be the reason, why it is close to the lower limit of the previously reported values.

\subsection{Effective KIE: dilution and photochemical degradation in the free troposphere}

For the interpretation of data collected in the free troposphere we assume the following, simplified situation: (i) the PBL is well mixed and therefore at least its "upper surface" is quite homogeneous and constant with respect to toluene 


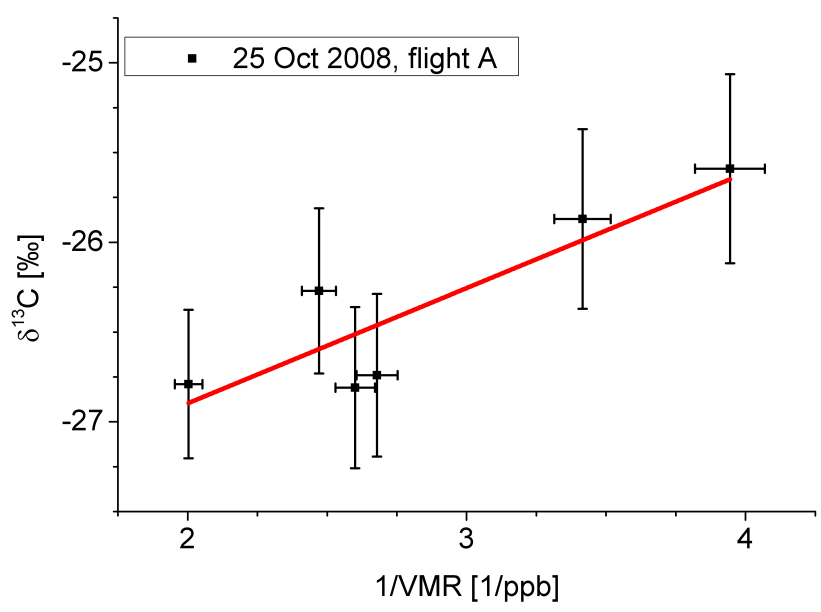

Fig. 15. $\delta^{13} \mathrm{C}$ values of toluene versus the inverse VMR; a linear fit (red line, Pearson $R=0.87$ ) is applied to the data.

VMR and isotope ratios; (ii) the toluene background concentration in the free troposphere is zero. In other words, all air parcels in the free troposphere, containing toluene in significant amounts, stem from the same source (the PBL) and undergo only dilution and photochemical processing (reactions with the $\mathrm{OH}$ radical). Assuming this, we can use Eq. (5) to calculate the effective KIE $\varepsilon_{\text {eff }}$, which contains information about the time constants of dilution and photochemical degradation.

To do so, we plot the measured toluene $\delta^{13} \mathrm{C}$ values versus the logarithm of the corresponding toluene VMR (see Fig. 16). Since we do not know the value of $c(0)$, characterising the "source", and since this value does not influence the calculation of $\varepsilon_{\mathrm{eff}}$, we just set $c(0)=1 \mathrm{ppt}$ to get rid of the units. Data from the PBL and the LFT are clearly distinguishable in Fig. 16, except for one sample, which was collected in the LFT but shows a rather PBL-like $\delta^{13} \mathrm{C} / \mathrm{VMR}$ characteristic. Therefore, this sample is excluded from the further analysis.

Fifteen samples from the LFT remain, 12 collected on 2 November 2008 and 3 collected on 7 November 2008. To check whether these samples could be combined to one data set we apply two linear fits: one to the whole data set and one only to the data points of 2 November 2008. For the whole data set we find $\varepsilon_{\text {eff }}=5.6 \pm 0.9 \%$ and for the data of 2 November $2008 \varepsilon_{\mathrm{eff}}=4.1 \pm 1.1 \%$ o. These values match within their $\sigma$-intervals. Therefore, we conclude that the dynamical and photochemical situation did not change much over the time period from 2 November 2008 to 7 November 2008. This indicates that the results we get by using the whole data set are quite representative for this period. Both fits yield a high correlation coefficient (Pearson $R=-0.91$ and -0.94 , respectively), indicating that the data follow the theory nicely and the assumptions (i) and (ii) above are justified.

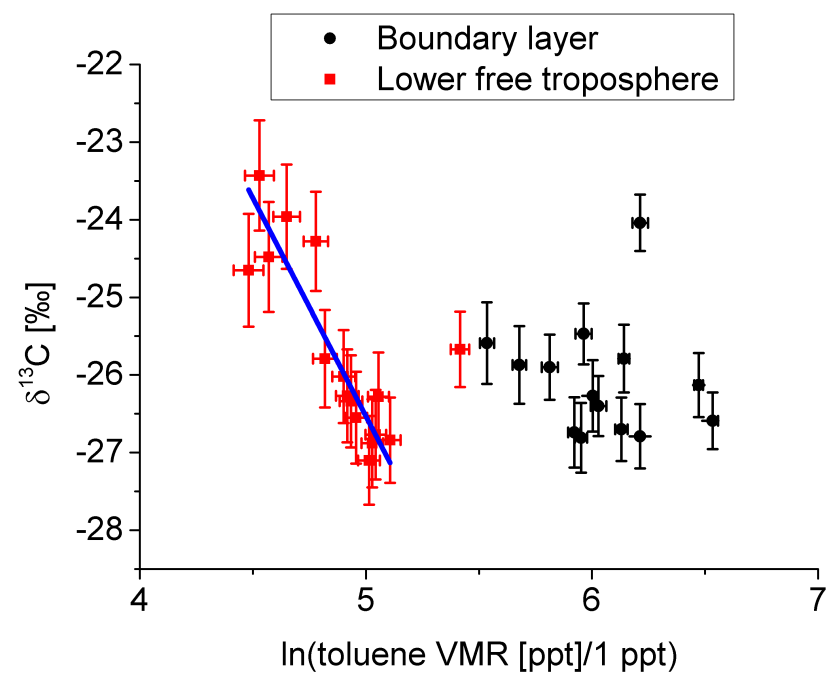

Fig. 16. Toluene $\delta^{13} \mathrm{C}$ values versus the logarithm of the corresponding VMR, divided by 1 ppt (see text for details); the height regimes (PBL and LFT) are clearly distinguishable. A linear fit (blue line, Pearson $R=-0.91$ ) is applied to the LFT data (one data point shows a rather PBL-like characteristic and is therefore excluded), yielding an effective KIE of $\varepsilon_{\text {eff }}=5.10 \pm 0.75 \%$.

If we consider the error bars, $\varepsilon_{\text {eff }}=5.6 \pm 0.9 \%$ equals $\varepsilon_{\mathrm{OH}}=5.95 \pm 0.28 \%$ o (see Sect. 2). In other words, our results show no significant influence of dilution in the LFT during the time period we span with our measurements. Decreases of the toluene VMR may be caused only by reactions with $\mathrm{OH}$. Since the free troposphere is much less turbulent than the boundary layer and photochemistry generally plays a dominant role there, our findings seem to be plausible.

\subsection{Photochemical age}

As described in Sect. 2 there are two ways to estimate the photochemical age $[\mathrm{OH}]_{\mathrm{avg}} t$ of the studied compounds in an air mass: on the one hand, based on the VMR ratio of two compounds with different lifetimes and a known emission ratio; on the other hand, based on the isotope ratio $\delta$ of a single compound with a known source isotope ratio $\delta_{0}$. To distinguish between the two methods, we want to refer to the results based on VMR as $\left([\mathrm{OH}]_{\mathrm{avg}} t\right)_{\mathrm{VMR}}$ and to the results based on isotope ratios as $\left([\mathrm{OH}]_{\mathrm{avg}} t\right)_{\delta}$. In the further discussion, we assume that toluene and benzene share the same sources (e.g. traffic), so we may use these two compounds to calculate $\left([\mathrm{OH}]_{\mathrm{avg}} t\right)_{\mathrm{VMR}}$ and compare the results to $\left([\mathrm{OH}]_{\mathrm{avg}} t\right)_{\delta}$ derived from toluene $\delta$ values.

The VMR emission ratios $c_{0}$ (toluene) $/ c_{0}$ (benzene) reported in the literature range from about two to about four (e.g. Roberts et al., 1984; Gelencsér et al., 1997; Kourtidis et al., 2002; de Gouw et al., 2005; Warneke et al., 2007). During ZEPTER-2 ground-based measurements yielded a ratio of 1.8 in the city of Ravensburg (Urban, 2010). Therefore we 


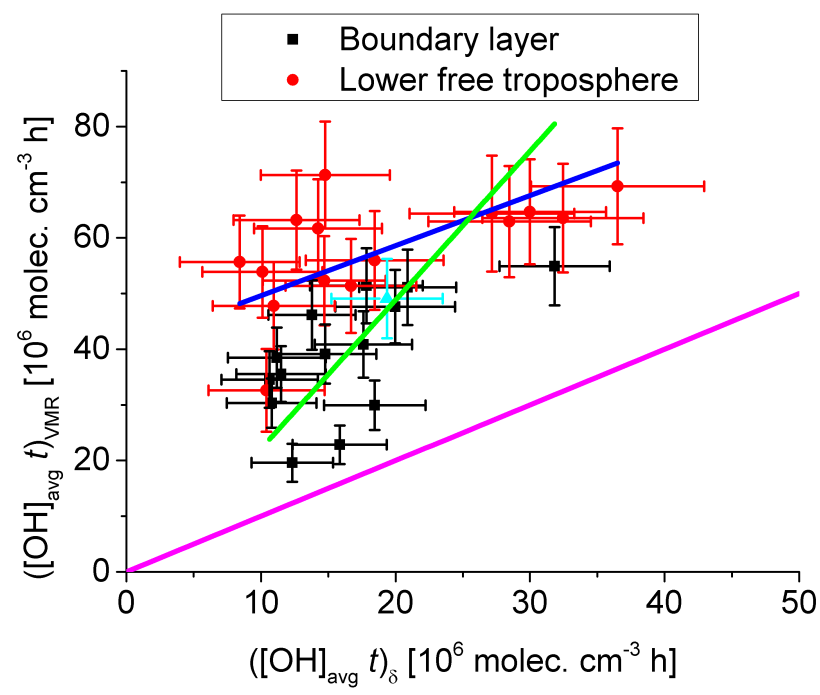

Fig. 17. Comparison of photochemical ages: $\left([\mathrm{OH}]_{\mathrm{avg}} t\right)_{\mathrm{VMR}}(\mathrm{de}-$ rived from toluene/benzene ratios) versus $\left([\mathrm{OH}]_{\mathrm{avg}} t\right)_{\delta}$ (derived from toluene $\delta^{13} \mathrm{C}$ values); the source values were estimated rather roughly (see text) and their uncertainties are not included in the error bars. Two linear fits are applied (green: to PBL data, slope $2.55 \pm 0.58$; blue: to free troposphere data, slope $0.91 \pm 0.29$; one data point, shown in light blue, from the LFT has a rather PBLlike isotope ratio/mixing ratio characteristic, see Fig. 16, and was therefore excluded from the fit). A line $y=x$ (purple) is shown for comparison.

estimate the emission ratio to be $c_{0}$ (toluene) $/ c_{0}$ (benzene) $\approx$ 1.8 ; the source $\delta$ value of toluene is estimated to be $\delta_{0}=$ $-28.2 \%$ (see Sect. 5.1).

Figure 17 shows the photochemical ages, based on these source values, for all data obtained during the campaign. Obviously, the absolute values of $\left([\mathrm{OH}]_{\mathrm{avg}} t\right)_{\mathrm{VMR}}$ and $\left([\mathrm{OH}]_{\mathrm{avg}} t\right)_{\delta}$ differ strongly. This is not surprising, since the source values used are just rough estimates and therefore may produce an offset between $\left([\mathrm{OH}]_{\mathrm{avg}} t\right)_{\mathrm{VMR}}$ and $\left([\mathrm{OH}]_{\mathrm{avg}} t\right)_{\delta}$.

Two separate linear fits are applied, to the PBL data and to the free troposphere data, which give slopes of $2.67 \pm 0.58$ and $0.90 \pm 0.31$, respectively. A slope unequal to one cannot be explained by inappropriate source values, since these do not influence the slope. As already mentioned (see Sect. 2), we would expect the two methods to give different results, if air masses of different ages have mixed. Obviously, in this case, heavy mixing in the PBL distorted $\left([\mathrm{OH}]_{\mathrm{avg}} t\right)_{\mathrm{VMR}}$.

The slope of the free troposphere data does not deviate significantly from one. This result supports the assumption we made in Sect. 5.2 (i.e. that the PBL acts as a more or less uniform VOC emission source for the free troposphere above), and it agrees well with the finding, that mixing plays a minor role in the free troposphere.

The strong scatter of the data is not surprising, either. Air mass exchanges between the PBL and the free troposphere mainly occur in the form of single, localised events (e.g. due to rising thermals). The PBL can therefore only on average be regarded as a homogenious VOC emission source (reflected by the "correct" slope of the fit line).

\section{Summary and conclusions}

We collected whole air samples in the PBL and the LFT and afterwards analysed them in the laboratory with respect to toluene and benzene VMR as well as toluene $\delta^{13} \mathrm{C}$ values. The GC-C-IRMS in use was carefully calibrated and characterised in order to identify possible problems and to determine the measurement errors. For sample volumes of $15 \mathrm{Ln}$ (the typical sample size), the precision of the measured isotope ratios was well below $1 \%$ at toluene VMR above $100 \mathrm{pptV}$, and below $0.5 \%$ at VMR above $250 \mathrm{pptV}$.

During a vertical profile flight over the Lake Constance, we sampled air masses containing rather fresh emissions of toluene in the PBL. Using the concept of two-endpoint mixing, we estimated a toluene source isotope ratio of $\delta_{0}=$ $-28.2 \pm 0.5 \%$.

We applied the concept of the effective KIE on the data obtained in the LFT and found the toluene VMR in this layer to be affected much more by photochemical degradation than by dilution processes: considering the error bars, we found no evidence for dilution in the LFT. Concerning the VMR and isotope ratio characteristics, samples in the LFT differed strongly from those in the PBL, allowing the two regimes to be clearly distinguished.

The photochemical ages of air masses were calculated in two different ways, based on toluene and benzene VMR as well as toluene isotope ratios. The two methods yielded quite different results for the PBL, probably due to strong mixing in that regime. In the LFT the calculated photochemical ages correlate with a slope of $0.90 \pm 0.31$, indicating again that the effect of mixing processes was rather weak in the LFT during the measurements.

Although the number of measurements in the present study is rather small, our results show that stable carbon isotope ratios of VOC can be measured with sufficient precision in the PBL and the LFT to gain valuable information about photochemical and dynamical processes in the atmosphere. Our study thus is an important proof of concept and encourages further activities, which promise to considerably enhance our knowledge on VOC source characteristics, transport and exchange processes, as well as the photochemical state of air masses.

Acknowledgements. We gratefully thank M. Gallus and the Atmospheric Chemistry Group at the University of Wuppertal for measuring VOC mixing ratios in standard B. We further thank F. Holland (Research Centre Jülich) for his help in the instrument certification and for providing the meteorological data and the teams of ZLT Zeppelin Luftschifftechnik GmbH\&Co KG and Deutsche Zeppelin-Reederei $\mathrm{GmbH}$ for helpful cooperation and 
logistical support. Special thanks go to F. Bühler, H.-P. Heuser, P. Knieling, C. Linke, and H. Spahn for their support during ZEPTER-2 and to C. Linke and D. Offermann for many helpful discussions during the preparation of this paper. We thank I. Gensch and J. Rudolph for their reviews and their constructive suggestions, which helped to improve the paper. The ZEPTER-2 project was financially supported by the German Federal Ministry of Education and Research under grant number 01LP0803A.

Edited by: U. Pöschl

\section{References}

Anderson, R., Czuba, E., Ernst, D., Huang, L., Thompson, A., and Rudolph, J.: Method for measuring carbon kinetic isotope effects of gas-phase reactions of light hydrocarbons with the hydroxyl radical, J. Phys. Chem. A, 107, 6191-6199, doi:10.1021/jp034256d, 2003.

Anderson, R., Iannone, R., Thompson, A., Rudolph, J., and Huang, L.: Carbon kinetic isotope effects in the gas-phase reactions of aromatic hydrocarbons with the $\mathrm{OH}$ radical at $296 \pm 4 \mathrm{~K}$, Geophys. Res. Lett., 31, L15108, doi:10.1029/2004GL020089, 2004a.

Anderson, R., Huang, L., Iannone, R., Thompson, A., and Rudolph, J.: Carbon kinetic isotope effects in the gas phase reactions of light alkanes and ethene with the $\mathrm{OH}$ radical at $296 \pm 4 \mathrm{~K}$, J. Phys. Chem. A, 108, 11537-11544, doi:10.1021/jp0472008, 2004b.

Anderson, R.: Carbon kinetic isotope effects in the gas-phase reactions of nonmethane hydrocarbons with hydroxyl radicals and chlorine atoms, Ph.D. thesis, York University, Toronto, Canada, 2005.

Atkinson, R. and Lloyd, A.: Evaluation of kinetic and mechanistic data for modelling of photochemical smog, J. Phys. Chem. Ref. Data, 13, 315-444, doi:10.1063/1.555710, 1984.

Brand, W. A.: Mass spectrometer hardware for analyzing stable isotope ratios, in: Handbook of Stable Isotope Analytical Techniques, Vol. 1, edited by: de Groot, P. A., Elsevier B.V., Amsterdam, the Netherlands, 835-856, 2004.

Craig, H.: Isotopic standards for carbon and oxygen and correction factors for mass-spectrometric analysis of carbon dioxide, Geochim. Cosmochim. Ac., 12, 133-149, 1957.

de Gouw, J. A., Middlebrook, A. M., Warneke, C., Goldan, P. D., Kuster, W. C., Roberts, J. M., Fehsenfeld, F. C., Worsnop, D. R., Canagaratna, M. R., Pszenny, A. A. P., Keene, W. C., Marchewka, M., Bertman, S. B., and Bates, T. S.: Budget of organic carbon in a polluted atmosphere: results from the New England Air Quality Study in 2002, J. Geophys. Res., 110, D16305, doi:10.1029/2004JD005623, 2005.

Farkas, E., Szilágyi, I., Dóbé, S., Bérces, T., and Márta, F.: Kinetic isotope effect in the reaction of $\mathrm{OH}$ radical with acetone- $D_{6}$, React. Kinet. Catal. L., 80, 351-358, doi:10.1023/B:REAC.0000006145.52881.dc, 2003.

Fasano, G. and Vio, R.: Fitting a straight line with errors on both coordinates, Bull. Inform. CDS, 35, 191-196, 1988.

Gelencsér, A., Siszler, K., and Hlavay, J.: Toluene-Benzene concentration ratio as a tool for characterizing the distance from vehicular emission sources, Environ. Sci. Technol., 31, 2869-2872, doi:10.1021/es970004c, 1997.
Gensch, I., Laumer, W., Stein, O., Kammer, B., Hohaus, T., Saathoff, H., Wegener, R., Wahner, A., and KiendlerScharr, A.: Temperature dependence of the kinetic isotope effect in $\beta$-pinene ozonolysis, J. Geophys. Res., 116, D20301, doi:10.1029/2011JD016084, 2011.

Gerbig, C., Schmitgen, S., Kley, D., Volz-Thomas, A., Dewey, K., and Haaks, D.: An improved fast-response vacuum-UV resonance flourescence CO instrument, J. Geophys. Res., 104, 16991704, 1999.

Goldstein, A. and Shaw, S.: Isotopes of volatile organic compounds: an emerging approach for studying atmospheric budgets and chemistry, Chem. Rev., 103, 5025-5048, doi:10.1021/cr0206566, 2003.

Häseler, R., Brauers, T., Holland, F., and Wahner, A.: Development and application of a new mobile LOPAP instrument for the measurement of HONO altitude profiles in the planetary boundary layer, Atmos. Meas. Tech. Discuss., 2, 2027-2054, doi:10.5194/amtd-2-2027-2009, 2009.

Hembeck, L.: Aufbau eines dynamischen Gasmischsystems, B.Sc. thesis, University of Wuppertal, Wuppertal, Germany, 2008.

Holloway, J. S., Jakoubek, R. O., Parrish, D. D., Gerbig, C., VolzThomas, A., Schmitgen, S., Fried, A., Wert, B., Henry, B., and Drummond, J. R.: Airborne intercomparison of vacuum ultraviolet flourescence and tunable diode laser absorption measurements of tropospheric carbon monoxide, J. Geophys. Res., 105, 24251-24261, 2000.

Iannone, R., Koppmann, R., and Rudolph, J.: A technique for atmospheric measurements of stable carbon isotope ratios of isoprene, methacrolein and methyl vinyl ketone, J. Atmos. Chem., 58, 181-202, doi:10.1007/s10874-007-9087-5, 2007.

Iannone, R., Koppmann, R., and Rudolph, J.: The stable-carbon kinetic isotope effects of the reactions of isoprene, methacrolein and methyl vinyl ketone with ozone in the gas phase, Atmos. Environ., 42, 8728-8737, doi:10.1016/j.atmosenv.2008.08.035, 2008.

Iannone, R., Koppmann, R., and Rudolph, J.: ${ }^{12} \mathrm{C} /{ }^{13} \mathrm{C}$ kinetic isotope effects of the gas-phase reactions of isoprene, methacrolein and methyl vinyl ketone with $\mathrm{OH}$ radicals, Atmos. Environ., 43, 3103-3110, doi:10.1016/j.atmosenv.2009.03.006, 2009.

Kourtidis, K. A., Ziomas, I., Zerefos, C., Kosmidis, E., Symeonidis, P., Christophilopoulos, E., Karathanassis, S., and Mploutsos, A.: Benzene, toluene, ozone, $\mathrm{NO}_{2}$ and $\mathrm{SO}_{2}$ measurements in an urban street canyon in Thessaloniki, Greece, Atmos. Environ., 34, 5355-5364, doi:10.1016/S1352-2310(02)00580-0, 2002.

Leckrone, K. J. and Hayes, J. M.: Water-induced errors in continuous-flow carbon isotope ratio mass spectrometry, Anal. Chem., 70, 2737-2744, doi:10.1021/ac9803434, 1998.

Linke, C.: Entwicklung und Anwendung von Analysemethoden und Auswertealgorithmen zur Untersuchung von Verhältnissen stabiler Kohlenstoffisotope in atmosphärischen leichtflüchtigen organischen Verbindungen, Ph.D. thesis, University of Wuppertal, Wuppertal, Germany, 2012.

McKeen, S. A., Trainer, M., Hsie, E. Y., Tallamraju, R. K., and Liu, S. C.: On the indirect determination of atmospheric OH radical concentrations from reactive hydrocarbon measurements, J. Geophys. Res., 95, 7493-7500, doi:10.1029/JD095iD06p07493, 1990.

McKeen, S. A., Liu, S. C., Hsie, E.-Y., Lin, X., Bradshaw, J. D., Smyth, S., Gregory, G. L., and Blake, D. R.: Hydrocarbon ratios 
during PEM-WEST A: a model perspective, J. Geophys. Res., 101, 2087-2109, doi:10.1029/95JD02733, 1996.

Nara, H., Toyoda, S., and Yoshida, N.: Measurements of stable carbon isotopic composition of ethane and propane over the western North Pacific and eastern Indian Ocean: A useful indicator of atmospheric transport processes, J. Atmos. Chem., 56, 293-314, doi:10.1007/s10874-006-9057-3, 2007.

Parrish, D. D., Hahn, C. J., Williams, E. J., Norton, R. B., Fehsenfeld, F. C., Singh, H. B., Shetter, J. D., Gandrud, B. W., and Ridley, B. A.: Indications of photochemical histories of Pacific air masses from measurements of atmospheric trace species at Point Arena, California, J. Geophys. Res., 97, 15883-15901, doi:10.1029/92JD01242, 1992.

Redeker, K. R., Davis, S., and Kalin, R. M.: Isotope values of atmospheric halocarbons and hydrocarbons from Irish urban, rural and marine locations, J. Geophys. Res., 112, D16307, doi:10.1029/2006JD007784, 2007.

Reimann, S. and Lewis, A. C.: Anthropogenic VOCs, in: Volatile Organic Compounds in the Atmosphere, edited by: Koppmann, R., Blackwell Publishing, Oxford, UK, 33-81, 2007.

Roberts, J. M., Fehsenfeld, F. C., Liu, S. C., Bollinger, M. J., Hahn, C., Albritton, D. L., and Sievers, R. E.: Measurements of aromatic hydrocarbon ratios and $\mathrm{NO}_{\mathrm{x}}$ concentrations in the rural troposphere: observation of air mass photochemical aging and $\mathrm{NO}_{\mathrm{x}}$ removal, Atmos. Environ., 18, 2421-2432, doi:10.1016/0004-6981(84)90012-X, 1984.

Rudolph, J.: Gas Chromatography-Isotope Ratio Mass Spectrometry, in: Volatile Organic Compounds in the Atmosphere, edited by: Koppmann, R., Blackwell Publishing, Oxford, UK, 388-466, 2007.

Rudolph, J. and Czuba, E.: On the use of isotopic composition measurements of volatile organic compounds to determine the "photochemical age" of an air mass, Geophys. Res. Lett., 27, 38653868, doi:10.1029/2000GL011385, 2000.

Rudolph, J. and Johnen, F. J.: Measurements of light atmospheric hydrocarbons over the Atlantic in regions of low biological activity, J. Geophys. Res., 95, 20583-20591, doi:10.1029/JD095iD12p20583, 1990.

Rudolph, J., Lowe, D. C., Martin, R. J., and Clarkson, T. S.: A novel method for compound specific determination of $\delta^{13} \mathrm{C}$ in volatile organic compounds at ppt levels in ambient air, Geophys. Res. Lett., 24, 659-662, doi:10.1029/97GL00537, 1997.

Rudolph, J., Czuba, E., and Huang, L.: The stable carbon isotope fractionation for reactions of selected hydrocarbons with $\mathrm{OH}-$ radicals and its relevance for atmospheric chemistry, J. Geophys. Res., 105, 29329-29346, doi:10.1029/2000JD900447, 2000.

Rudolph, J., Czuba, E., Norman, A. L., Huang, L., and Ernst, D.: Stable carbon isotope composition of nonmethane hydrocarbons in emissions from transportation related sources and atmospheric observations in an urban atmosphere, Atmos. Environ., 36, 11731181, doi:10.1016/S1352-2310(01)00537-4, 2002.
Rudolph, J., Anderson, R. S., v. Czapiewski, K., Czuba, E., Ernst, D., Gillespie, T., Huang, L., Rigby, C., and Thompson, A. E.: The stable carbon isotope ratio of biogenic emissions of isoprene and the potential use of stable isotope ratio measurements to study photochemical processing of isoprene in the atmosphere, J. Atmos. Chem., 44, 39-55, doi:10.1023/A:1022116304550, 2003.

Saito, T., Tsunogai, U., Kawamura, K., Nakatsuka, T., and Yoshida, N.: Stable carbon isotopic compositions of light hydrocarbons over the western North Pacific and implication for their photochemical ages, J. Geophys. Res., 107, ACH 2-1-ACH 2-9, doi:10.1029/2000JD000127, 2002.

Saito, T., Kawamura, K., Tsunogai, U., Chen, T.-Y., Matsueda, H., Nakatsuka, T., Gamo, T., Uematsu, M., and Huebert, B. J.: Photochemical histories of nonmethane hydrocarbons inferred from their stable carbon isotope ratio measurements over east Asia, J. Geophys. Res., 114, D11303, doi:10.1029/2008JD011388, 2009.

Santrock, J., Studley, S. A., and Hayes, J. M.: Isotopic analyses based on the mass spectrum of carbon dioxide, Anal. Chem., 57, 1444-1448, doi:10.1021/ac00284a060, 1985.

Spahn, H.: Untersuchungen der Verhältnisse stabiler Kohlenstoffisotope in atmosphärisch relevanten VOC in Simulations- und Feldexperimenten, Ph.D. thesis, University of Wuppertal, Wuppertal, Germany, 2009.

Thompson, A. E.: Stable carbon isotope ratios of nonmethane hydrocarbons and halocarbons in the atmosphere, Ph.D. thesis, York University, Toronto, Canada, 2003.

Tsunogai, U., Yoshida, N., and Gamo, T.: Carbon isotopic compositions of $\mathrm{C}_{2}-\mathrm{C}_{5}$ hydrocrabons and methyl chloride in urban, coastal, and maritime atmospheres over the western North Pacific, J. Geophys. Res., 104, 16033-16039, doi:10.1029/1999JD900217, 1999.

Urban, S.: Charakterisierung der Quellverteilung von Feinstaub und Stickoxiden in ländlichem und städtischem Gebiet, Ph.D. thesis, University of Wuppertal, Wuppertal, Germany, 2010.

v. Czapiewski, K., Czuba, E., Huang, L., Ernst, D., Norman, A. L., Koppmann, R., and Rudolph, J.: Isotopic composition of nonmethane hydrocarbons in emissions from biomass burning, J. Atmos. Chem., 43, 45-60, doi:10.1023/A:1016105030624, 2002.

Warneke, C., McKeen, S. A., de Gouw, J. A., Goldan, P. D., Kuster, W. C., Holloway, J. S., Williams, E. J., Lerner, B. M., Parrish, D. D., Trainer, M., Fehsenfeld, F. C., Kato, S., Atlas, E. L., Baker, A., and Blake, D. R.: Determination of urban volatile organic compound emission ratios and comparison with an emissions database, J. Geophys. Res., 112, D10S47, doi:10.1029/2006JD007930, 2007.

Williams, J. and Koppmann, R.: Volatile organic compounds in the atmosphere: an overview, in: Volatile Organic Compounds in the Atmosphere, edited by: Koppmann, R., Blackwell Publishing, Oxford, UK, 1-32, 2007. 